\title{
Costorage and Corelease of Modulatory Peptide Cotransmitters with Partially Antagonistic Actions on the Accessory Radula Closer Muscle of Aplysia californica
}

\author{
F. S. Vilim, ${ }^{1}$ D. A. Price, ${ }^{2}$ W. Lesser, ${ }^{2}$ I. Kupfermann, ${ }^{1}$ and K. R. Weiss ${ }^{3}$ \\ ${ }^{1}$ Center for Neurobiology and Behavior, College of Physicians and Surgeons, Columbia University, New York, New York \\ 10032, ${ }^{2}$ C. V. Whitney Laboratories, University of Florida, St. Augustine, Florida 32086, and ${ }^{3}$ Department of Physiology \\ and Biophysics, Mount Sinai School of Medicine, New York, New York 10029
}

\begin{abstract}
Many neurons that contain a classical neurotransmitter also contain modulatory peptides, but it has been difficult to establish unequivocally that these peptides are functional cotransmitters. Here, we provide evidence for functional cotransmission in a neuromuscular system of Aplysia. Using immunocytochemical techniques, we localize members of two peptide families, the small cardioactive peptides (SCPs) and the buccalins (BUCs), to a single subset of dense-core vesicles in the terminals of the cholinergic motorneuron B15. We describe a new preparation and method for the direct detection of released peptides and show that the SCPs and BUCs are released when neuron B15 is intracellularly stimulated. Consistent with their subcellular localization, the SCPs and BUCs are released in a stoichiometric ratio that is constant across conditions that change the absolute amount of peptides released. Peptide release is calcium-dependent
\end{abstract}

but does not require muscle contractions. Thus, the release cannot be attributed to a displacement of peptides that may be present in the extracellular space. In previous studies, we characterized the physiological firing patterns of neuron B15. Here, we simulate these firing patterns and show that peptide release occurs. Additionally, we find that significant quantities of material are released under behaviorally relevant conditions. We find that concentrations of released peptides in the muscle are in the concentration range in which exogenously applied peptides exert characterized modulatory actions on muscle contractions. Together, our findings provide strong support for the hypothesis that peptides contained in neuron B15 are functional cotransmitters.

Key words: neuropeptides; dense-core vesicles; peptide release; Aplysia; cotransmission; EM immunocytochemistry; motor neuron; modulation
When several putative transmitters are found in a single neuron, it is easy to assume that they function as cotransmitters. This supposition, however, has been difficult to verify. A recent review of cotransmission (Kupfermann, 1991) concluded that there was no definitive evidence that cotransmission occurs under normal physiological conditions. In general, the greatest obstacle to establishing functional cotransmission has been the difficulty in demonstrating that putative cotransmitters are released when neurons fire in physiological patterns.

To overcome difficulties in the study of cotransmission, simpler, more experimentally advantageous model systems were developed. One such system consists of the accessory radula closer (ARC) muscle and its cholinergic motorneurons, B15 and B16. $\mathrm{B} 15$ and B16 synthesize peptides that potentiate contraction size and relaxation rate. B15 synthesizes (Cropper et al., 1987a) the small cardioactive peptides (SCPs), and B16 synthesizes the myomodulins (MMs) (Cropper et al., 1987b, 1991; Brezina et al., 1995). In addition, both motorneurons synthesize the buccalins (BUCs), which depress muscle contractions (Cropper et al., 1988, 1990a; Vilim et al., 1994).

Studies of peptide release in the ARC (Whim and Lloyd, 1989,

Received June 24, 1996; revised Sept. 20, 1996; accepted Sept. 24, 1996.

This work was supported in part by National Institutes of Health Grants $\mathrm{MH}$ 36730, MH50235, and GM32009.

Correspondence should be addressed to Klaudiusz R. Weiss, Department of Physiology and Biophysics, Mt. Sinai School of Medicine, 1 Gustave L. Levy Place, New York, NY 10029.

Copyright (C) 1996 Society for Neuroscience $0270-6474 / 96 / 168092-13 \$ 05.00 / 0$
1990; Cropper et al., 1990b; Hooper et al., 1994a,b; Probst et al., 1994) have taken two approaches. It has been demonstrated (1) that prolonged stimulation of B15 at physiological frequencies decreases SCP levels in nerve terminals, and (2) that physiological stimulation of $\mathrm{B} 15$ produces second messenger-mediated changes in ARC muscle that cannot be accounted for by ACh action but are produced by application of the SCPs. Although these findings suggest that the SCPs are released under physiological conditions, alternative interpretations are possible. In depletion experiments, stimulation lasted up to $5 \mathrm{hr}$. Depletion could have resulted from toxic effects of increased calcium levels caused by the maintained stimulation. When biochemical changes in muscles were observed, it could be argued that motor neurons release unknown substances and that these could produce biochemical changes observed in the muscle.

Additionally, previous experiments have sought only to demonstrate the release of the peptides that exert potentiating actions. Because B15 also synthesizes the BUCs, fundamental questions concerning the physiological consequences of peptide release in the ARC remain unanswered. Thus, are the BUCs and the SCPs packaged in the same vesicles and coreleased, or are they packaged in different vesicles and differentially released (Sossin et al., 1989; Wang and Scheller, 1991)? In either case, the characteristics of motor neuron firing that result in the release of these peptides have to be determined if one is to understand the functional role of cotransmission. Therefore, in the studies presented in this paper and its companion (this issue), we have undertaken (1) to determine the subcellular distribution of neuropeptides in neuron 
B15, (2) to develop a preparation that can be used to investigate peptide release under physiological conditions, and (3) to define how behaviorally relevant changes in the B15 activity determine the characteristics of peptide release. Taken together, the purpose of our studies was to provide evidence for the existence of cotransmission and to elucidate the behavioral function(s) of this mode of signaling.

\section{MATERIALS AND METHODS}

Animals. Specimens of Aplysia californica were obtained from Marinus. The animals were maintained at $14-16^{\circ} \mathrm{C}$ on a $12 \mathrm{hr}$ light/dark cycle and fed every $3 \mathrm{~d}$. Animals in the range of 50-100 gm were used for the morphology experiments, and animals in the range of 300-600 gm were used for release experiments. Isotonic $\mathrm{MgCl}_{2}$ (25-50\% body weight) was used to immobilize the animals, and all stages of the dissection were carried out in the animals' own hemolymph containing the added $\mathrm{MgCl}_{2}$.

Backfills. A unilateral ARC preparation was pinned out on SYLGARD (Dow Corning, Corning, NY) in a 3-inch-deep dish. A 3-inch-deep subchamber was sealed around the distal portion of the ARC with silicone grease. The space outside the subchamber was filled almost to the top with L-15 (adjusted to Aplysia salinity and buffered with $10 \mathrm{~mm}$ HEPES to $\mathrm{pH}$ 7.6). The fluid inside the subchamber was evacuated, and the viability of the seal was evaluated. If the seal was adequate, the filling solution $\left(1 \mathrm{M} \mathrm{CoCl}_{2}\right.$ or $\left.1 \mathrm{M} \mathrm{NiCl}_{2}\right)$ was added to the subchamber in amounts sufficient to completely submerge the ARC $(\sim 100 \mu \mathrm{l})$. The hydrostatic back pressure prevented the nonspecific diffusion of filling solution. The preparation was then placed at $4^{\circ} \mathrm{C}$, and the filling solution was changed daily. After 2-3 d, the filling solution in the subchamber was washed out with several changes of artificial seawater (ASW), and the preparation was pinned out in a smaller dish for developing. The preparation was developed by the addition of a one-tenth volume of saturated dithio-oximide in $95 \%$ ethanol, which produces a blue-black precipitate with $\mathrm{NiCl}_{2}$ and a red-brown precipitate with $\mathrm{CoCl}_{2}$ (Quicke and Brace, 1979). After the filled cells stopped getting darker $(\sim 10 \mathrm{~min})$, the preparation was washed with ASW and fixed with $4 \%$ paraformaldehyde overnight. The tissue was washed free of fixative, dehydrated in a series of ethanols, and viewed in methyl salycilate.

Antibodies. The rabbit antibody to SCPb used for immunocytochemistry was a kind gift from Dr. Richard Scheller (Stanford University, Stanford, $\mathrm{CA}$ ). The rabbit antibody to $\mathrm{SCPb}$ used for radioimmunoassay (RIA) was a kind gift from Dr. H. R. Morris (Imperial College). The rabbit antibody to buccalin used for immunocytochemistry and RIA was raised against BUCa coupled to bovine serum albumin (BSA). The rat antibody to $\mathrm{SCPb}$ used for immunocytochemistry was raised against peptide coupled to bovine thyroglobulin (BTG). The peptides were coupled to the carrier protein with 1-ethyl-3-(3-dimethylaminopropyl)carbodiimide (EDC). The rabbit buccalin antibodies were prepared by Babco (Richmond, CA), and the rat SCP antibody was made in house. All reagents were purchased from Sigma (St. Louis, MO) except the peptides, which were synthesized by Applied Biosystems (Foster City, CA).

LM immunocytochemistry. A number of methods were used, but the procedure that consistently gave superior results was one adapted from Llewellyn-Smith et al. (1985). All of the procedures were carried out at room temperature unless stated otherwise. The ganglia and muscles were excised, washed with a 1:1 mixture of ASW and isotonic $\mathrm{MgCl}_{2}$, and pinned out on SYLGARD slabs. The slabs were placed in $50 \mathrm{ml}$ conical tubes containing $25 \mathrm{ml}$ of freshly prepared fixative (4\% paraformaldehyde, $0.2 \%$ picric acid, $25 \%$ sucrose, $0.1 \mathrm{~m}$ sodium phosphate, $\mathrm{pH} 7.6$ ), shaken for $30 \mathrm{~min}$, and left to fix overnight on a rocker. After fixation, the tissue was rinsed with several changes of distilled water until the yellow color dissipated. The tissue was then washed with several changes of $50 \%$ ethanol and transferred to $50 \%$ ethanol $3 \% \mathrm{H}_{2} \mathrm{O}_{2}$ for $1 \mathrm{~d}$ to permeabilize the tissue and reduce background fluorescence. After a wash with several changes of distilled water, nonspecific staining was blocked by overnight incubation with $10 \%$ normal donkey serum (NDS) in RIA buffer (see below). The tissue was exposed to the primary antibody in the same buffer for 2-7 d, washed with RIA buffer with several changes for $1 \mathrm{~d}$, and placed in fluorescently labeled (lissamine rhodamine and DTAF) secondary antibody raised in donkey (Jackson ImmunoResearch, West Grove, PA) for $2 \mathrm{~d}$. Secondary antibody was washed out with several changes of RIA buffer for $1 \mathrm{~d}$ and viewed on a Leitz microscope equipped with epifluorescence and the appropriate filterpacks for rhodamine (N-2) and fluorescein (D). Selected specimens were photographed on T-Max ASA 400 film (Eastman Kodak, Rochester, NY).
EM immunocytochemistry. The procedure was adapted from Reed et al. (1988) and Merighe et al. (1989). Tissue was pinned out on SYLGARD slabs, placed in a conical tube with $30 \mathrm{ml}$ of fixative (4\% glutaraldehyde, $10 \%$ sucrose, $11 \mathrm{~mm}$ magnesium chloride, $0.2 \mathrm{~m}$ Na-HEPES, $\mathrm{pH}$ 7.6), shaken for $15 \mathrm{~min}$, and placed on a rocker for $3 \mathrm{hr}$. The fixative was washed away with several changes of buffer (fixative minus glutaraldehyde) during $3 \mathrm{hr}$. The tissue was stained en bloc with buffer containing $1 \%$ uranium acetate for $3 \mathrm{hr}$ and then post-fixed with $1 \%$ osmium tetroxide in buffer at $4^{\circ} \mathrm{C}$ for $1 \mathrm{hr}$. The tissue was washed with several changes of distilled water, dehydrated in an ethanol series, washed with propylene oxide, infiltrated with EMbed 812 , and polymerized at $60^{\circ} \mathrm{C}$ for 2 d. Ultrathin sections were cut on a Sorvall ultratome, and pale gold sections were collected on 200-mesh, thin-bar hex grids. The grid was then floated sequentially on both sides on saturated sodium metaperiodate, which etched both sides of the section; immersion during etching caused section detachment. The grids were then immersed in distilled water for $15 \mathrm{~min}$, followed by Tris-buffered saline (TBS), $\mathrm{pH}$ 8.2, for 15 min and then were blocked with $8 \%$ normal goat serum (NGS) in TBS for $1 \mathrm{hr}$. A 1:100 dilution of primary antibody in 4\% NGS-TBS was used to stain the sections overnight. The grids were washed 4 times for $30 \mathrm{~min}$ each with 4\% NGS-TBS, followed by $1 \mathrm{hr}$ in 1:4 dilution of gold labeled secondary antibodies (Amersham, Arlington Heights, IL) in 4\% NGSTBS. The grids were again washed 4 times for 30 min each with $4 \%$ NGS-TBS, followed by 2 times for 5 min each with 0.1 m PBS. The gold-labeled antibodies were fixed to the sections with $2 \%$ glutaraldehyde in $0.1 \mathrm{M}$ PBS and washed with several changes of $\mathrm{dH}_{2} \mathrm{O}$. The sections were lightly counterstained with 5\% aqueous uranyl acetate for 30-60 sec, followed by Reynolds lead citrate for 30-60 sec. Sections were examined and photographed with a JOEL $100 \mathrm{CX}$ at $80 \mathrm{kV}$. Electron microscopy supplies and reagents were obtained from EMS (Fort Washington, PA). Normal sera were obtained from Jackson ImmunoResearch.

Release preparation. The ARC-buccal ganglion preparation was isolated as described previously (Cohen et al., 1978) with some minor differences. The buccal and cerebral ganglia were dissected free, but the connection between nerve 3 and the buccal mass was kept intact. This nerve contains the axons of B15 and B16 that innervate the ARC. The connective tissue midway along the ARC was preserved because it houses the major artery used for perfusion. The distal end of the ARC was dissected free of the radular sac and ligated with 6-0 silk suture to prevent loss of perfusate via the distal cut end.

The ARC artery was cannulated with a 30 gauge blunt needle and perfused with ASW at $20 \mu \mathrm{l} / \mathrm{min}$ with a multistaltic pump. The dead volume of the perfusion system was $\sim 100 \mu$ l so that solutions perfusing the ARC could be changed while a constant flow rate was maintained. The perfused muscle was hung outside a $60 \mathrm{~mm}$ dish, and the nerve connecting the ARC to the ganglion was passed through a slit in the side of the dish, so that the buccal ganglion could be pinned inside the dish. The slit was filled with silicone grease, the ganglion was desheathed, and the ARC was partially encased with parafilm coated with silicone grease. The parafilm formed a subchamber around the ARC, preventing it from drying out, and the silicone grease prevented nonspecific adsorption of released peptides. The dish was clamped onto a platform with the ARC hanging off the side, permitting drops of ARC perfusate to form and fall freely. The drops were collected every $2.5 \mathrm{~min}$ into glass test tubes $(12 \times$ $75 \mathrm{~mm}$ ) that were then processed for RIA. The solution bathing the ganglion contained $25 \%$ isotonic $\mathrm{MgCl}_{2}$ to prevent spontaneous activity of the neurons in the ganglion. This arrangement ensured that only the motorneuron being fired could be responsible for the peptide released within the ARC. The motorneuron was impaled with two independent glass microelectrodes, one for recording voltage and one for injecting current. The resulting configuration of the release preparation is illustrated in Figure 1. The temperature of the preparation was maintained at $15 \pm 0.5^{\circ} \mathrm{C}$ (i.e., the temperature of the aquaria housing the animals) by cooling the room with an air conditioner.

$R I A$. A 3-( $p$-hydroxyphenyl)-propionic acid (desamino-tyrosyl) derivative of buccalin A was prepared by reaction of $1 \mu \mathrm{mol}$ of peptide, $1 \mu \mathrm{mol}$ of triethylamine, and $3 \mu \mathrm{mol}$ of Bolton-Hunter reagent [3- $(p-$ hydroxyphenyl)-propionic acid $N$-hydroxy-succinimide ester] in $100 \mu \mathrm{l}$ of dimethylformamide for $6 \mathrm{hr}$ at $4^{\circ} \mathrm{C}$ followed by purification on RP-HPLC with a $15-45 \%$ acetonitrile gradient with $0.01 \mathrm{M}$ TFA as counterion.

Peptides (the desaminotyrosinoyl-buccalin or $\mathrm{SCPb}$ ) were iodinated with ${ }^{125}$ I using chloramine-T as follows. To the peptide $(\sim 1 \mathrm{nmol}$ in $10 \mu \mathrm{l}$ of $0.5 \mathrm{M}$ phosphate buffer, $\mathrm{pH} 7.0$ ) was added the radioactive sodium iodide solution $(1.5 \mathrm{mCi}$ in $1-3 \mu \mathrm{l})$ followed by $5 \mu \mathrm{l}$ of chloramine-T solution (freshly prepared in the $0.5 \mathrm{M}$ phosphate buffer, $2 \mathrm{mg} / \mathrm{ml}$ ), and 


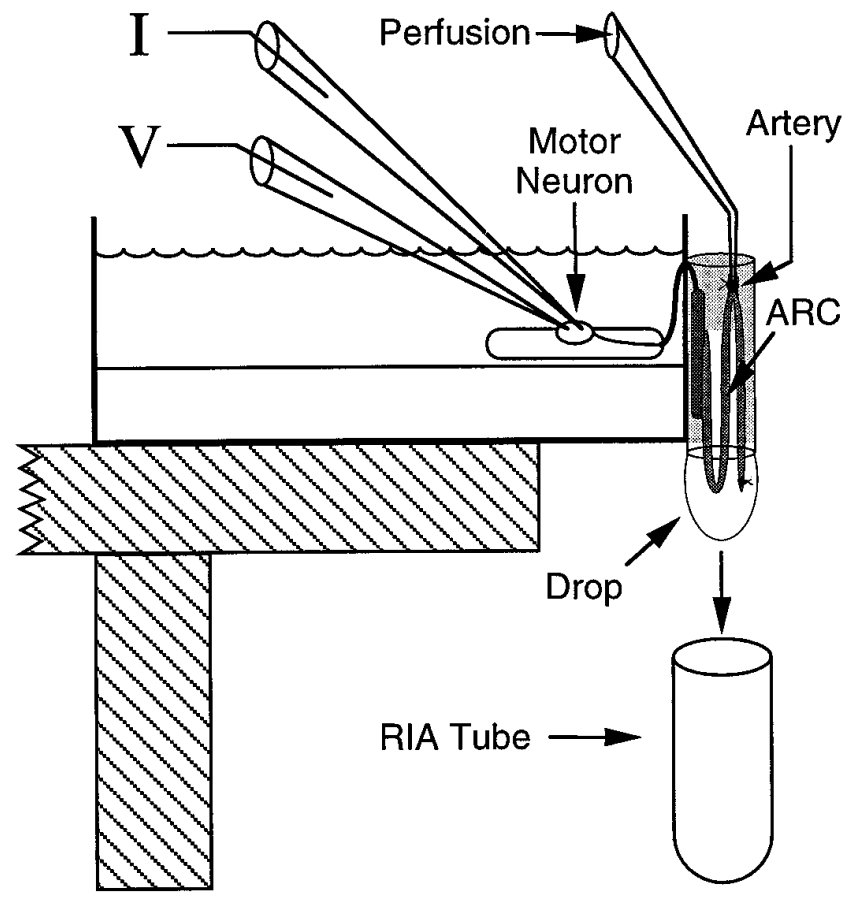

Figure 1. Diagram of the preparation used to measure peptide release within the ARC. The buccal ganglion is bathed in high- $\mathrm{Mg}^{2+} \mathrm{ASW}$ to prevent spontaneous neuronal activity. The motorneuron is impaled with two microelectrodes (one to measure voltage, the other to inject current). These conditions enable precise control over the firing of the motorneuron and ensure that only the motorneuron being fired is responsible for the peptide released within the ARC. The ARC (medium gray) is suspended outside the dish and encased in silicone grease (light gray) and parafilm to prevent dehydration. The nerve connecting the buccal ganglion to the ARC runs through a slit in the side of the dish that is subsequently filled with silicone grease to prevent leakage of solutions from the dish. The ARC is perfused via an artery midway along its length, and the perfusate is collected in drops directly into the tubes that are subsequently used for the measurement of their peptide content. The temperature and length of the ARC were also measured with a temperature probe mounted on an isotonic force transducer (not shown). The tip of the temperature probe was inserted at the bottom of the loop between the base muscle (dark gray) and the artery.

the solution was mixed well by repeated pipetting with an aerosol barrier tip. Sodium metabisulfite $(100 \mu \mathrm{l}$ of $5 \mathrm{mg} / \mathrm{ml}$ in the $0.5 \mathrm{M}$ phosphate buffer) was added 15-30 sec after the chloramine-T, and the solution was mixed by repeated pipetting for $1 \mathrm{~min}$. After another 4-5 min, the iodination mixture was applied to a Sep-Pak (C18, Waters Associates, Milford, MA) that had been wetted previously with acetonitrile and rinsed with distilled water. The Sep-Pak was washed with $20 \mathrm{ml}$ of water (discarded as waste), and the peptide was eluted with $80 \%$ aqueous acetonitrile containing $0.01 \mathrm{M}$ TFA (a total of $5 \mathrm{ml}$ collected in $1 \mathrm{ml}$ fractions). Usually, the first $1 \mathrm{ml}$ fraction was kept and the others discarded after counting revealed that the majority of the elutable radioactivity resided in the first fraction. The partially purified (by Sep-Pak) trace could be kept for several months in the freezer as a stock for HPLC purification of monoiodinated peptide. Because some uniodinated and unoxidized peptide remained in the Sep-Pak purified trace, it was treated with $1 \% \mathrm{H}_{2} \mathrm{O}_{2}$ for $1 \mathrm{hr}$ to fully oxidize all methionine residues to the sulfoxides. After this treatment, the desired monoiodo form of the peptide could be separated from both the uniodinated and the diiodinated forms on RP-HPLC with a gradient as above. Radioactive peaks corresponding to the monoiodinated form were lyophilized and resuspended in RIA buffer (154 mM NaCl, $10 \mathrm{mM} \mathrm{Na}_{2} \mathrm{HPO}_{4}, 50 \mathrm{~mm}$ EDTA, $0.25 \mathrm{~mm}$ merthiolate, $1 \%$ BSA, $\mathrm{pH} 7.5$ ) to a final activity of $10,000-15,000$ $\mathrm{cpm}$ per $100 \mu \mathrm{l}$. Antibodies were diluted in RIA buffer to a point at which $100 \mu \mathrm{l}$ would bind $\sim 50 \%$ of the counts in $100 \mu \mathrm{l}$ of iodinated peptide trace. The sample volume (blanks, peptide standards, perfusate) was 50 $\mu \mathrm{l}$ in each reaction. The reaction was carried out for $2-3 \mathrm{~d}$ at $4^{\circ} \mathrm{C}$ and was

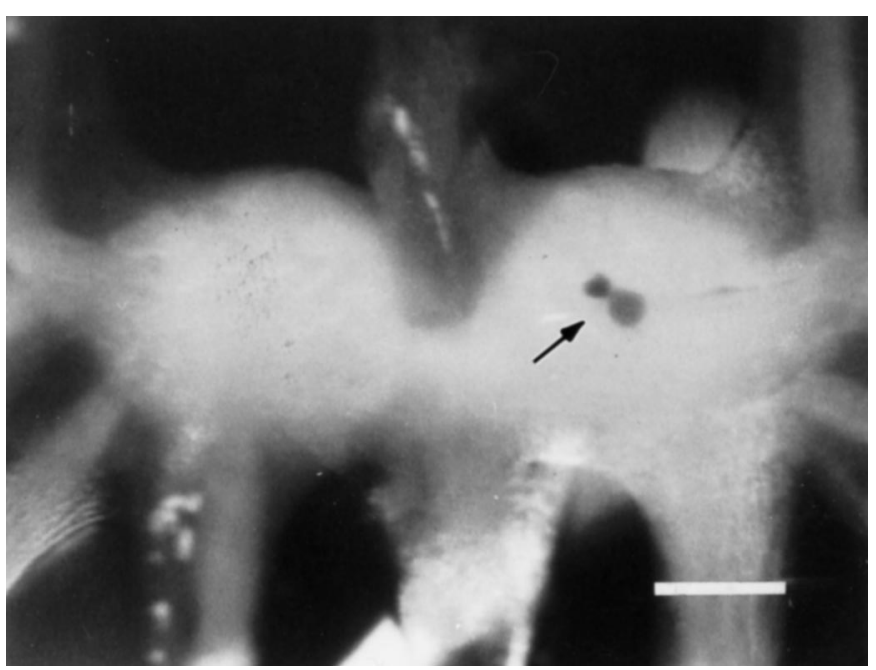

Figure 2. Cobalt backfill of a buccal ganglion from the ARC muscle. The arrow points to two neurons in the rostral aspect of the ventral motorneuron cluster stained for cobalt. The size and position of the neurons are consistent with the larger one being B15 and the smaller one being B16. Scale bar, $0.5 \mathrm{~mm}$. This agrees with the electrophysiological data indicating that the ARC is innervated by only two motorneurons.

terminated by the addition of $2 \mathrm{ml}$ of RIA charcoal $\left(10 \mathrm{mM} \mathrm{Na}_{2} \mathrm{HPO}_{4}\right.$, $0.25 \mathrm{~mm}$ merthiolate, $0.25 \%$ activated charcoal, $0.025 \% 70,000 \mathrm{kDa}$ dextran, $\mathrm{pH}$ 7.5). After $15 \mathrm{~min}$, the samples were spun to separate the charcoal and supernatant. The supernatant, containing the bound peptide, was decanted and counted in a gamma counter. Standard curves were generated from serial dilutions of peptide in ASW containing $1 \%$ BSA to prevent sticking of the peptide to the tubes and pipette tips. The sample volume was $50 \mu \mathrm{l}$, which matched the volume of the drops in the experiment, and each tube had half the peptide of the previous tube. A spreadsheet program (Kaleidagraph 2.1) was used to plot the standard curves, to convert counts bound to femtomoles of peptide in the unknowns, and to graph the data. A statistical analysis program (StatView 4.5 ) was used to perform a within-subjects repeated-measures ANOVA on relevant data to assess the overall level of statistical significance. Individual comparisons were performed using paired $t$ tests. All reagents were obtained from Sigma, except where noted otherwise.

\section{RESULTS}

The ARC is innervated by a limited number of neurons

Electrophysiological evidence indicates that B15 and B16 are the only motorneurons that innervate the ARC (Cohen et al., 1978). The results of ARC muscle backfills support this finding, because only two motorneurons were retrogradely labeled and their position and size correspond to those of cells B15 and B16 (Fig. 2). Some backfills also resulted in retrograde labeling of small neurons in the sensory cluster (Fiore and Geppetti, 1980), which apparently represent the sensory innervation of the ARC (data not shown). Thus, only a small number of neurons are known to innervate the ARC, thereby simplifying the identification of its processes.

\section{Antibody staining corresponds to the biochemical localization}

Figure 3, $A 1$ and $A 2$, shows the simultaneous staining of a buccal hemiganglion with a rabbit $\mathrm{BUCa}$ antibody and a rat $\mathrm{SCPb}$ antibody. The buccal hemiganglion shows cells in the positions, respectively, of B15 (white arrowheads), which stains for both SCP (A1) and buccalin (A2), and B16 (black arrowheads), which stains for buccalin alone. These patterns match the previously reported distribution of staining and biochemical localization in the buccal ganglion for SCP (Lloyd et al., 1987a; Church and Lloyd, 1991) 

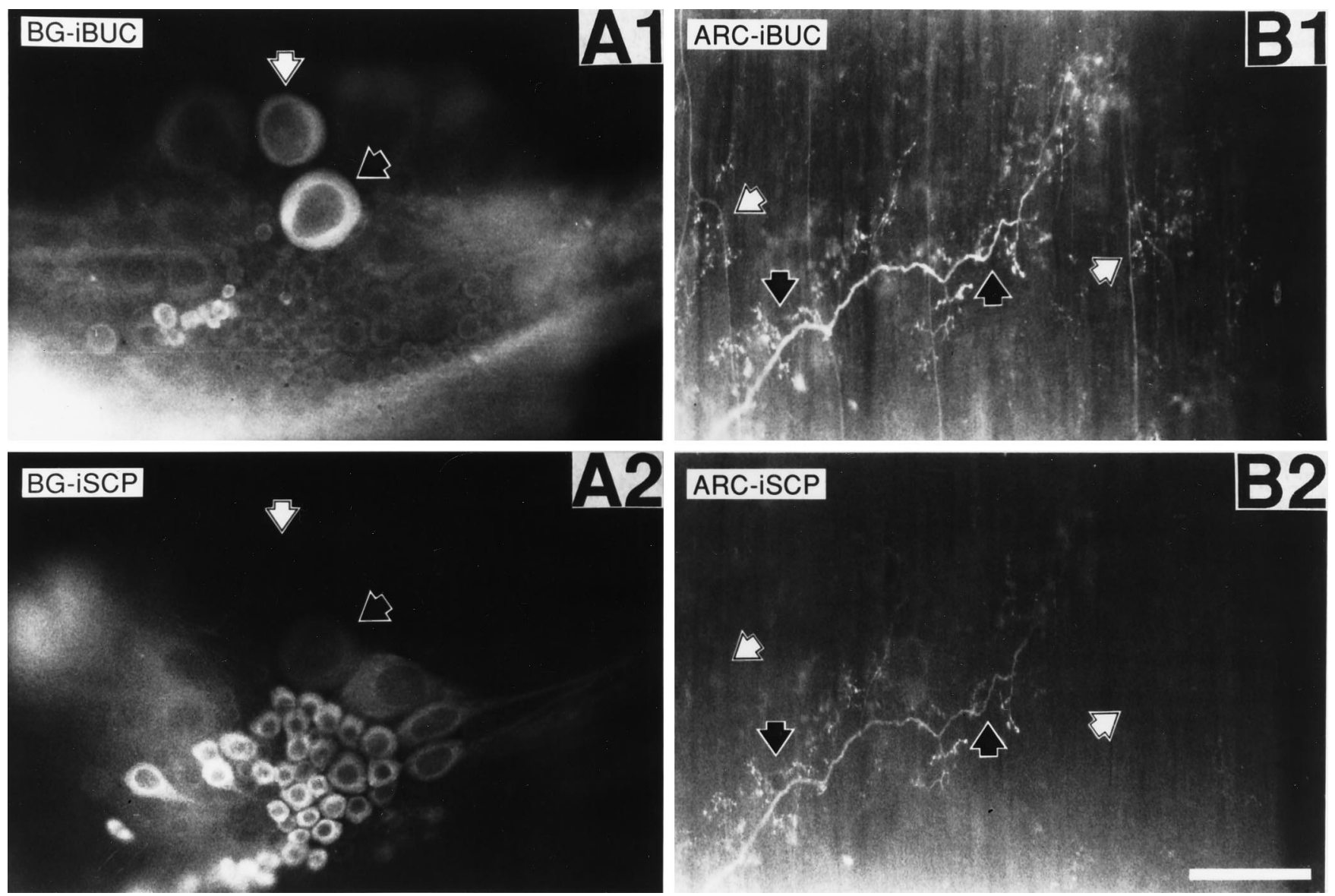

Figure 3. Buccalin and SCP immunostaining in whole mounts of buccal ganglion and ARC muscle. SCP was stained with a primary antibody generated in the rat and a lissamine rhodamine-conjugated, donkey anti-rat secondary antibody. Buccalin was stained using a primary antibody generated in the rabbit and a fluorescein-conjugated, donkey anti-rabbit secondary antibody. A1 shows buccalin immunostaining of the buccal hemiganglion with the commissure on the right, and $A 2$ shows SCP immunostaining of the same field. The black arrowheads point to a neuron staining for buccalin and SCP, which is of a size and position to be B15. No other cells in the buccal ganglion exhibited costaining for buccalin and SCP. White arrowheads point to a neuron staining for buccalin without staining for SCP, which is of a size and position to be B16. B1 shows buccalin immunostaining of the ARC, and B2 shows SCP immunoreactivity of the same field. The black arrowheads point to processes staining for buccalin and SCP, indicating that they belong to B15. White arrowheads point to processes staining for buccalin alone, indicating that they belong to B16. Notice that the B15 and B16 processes are often separated by many micrometers and seem to innervate spatially distinct areas of the ARC. Scale bar (shown in B2), $200 \mu \mathrm{m}$.

and buccalin (Miller et al., 1992). The distinct staining patterns of SCP $(A 2)$ and buccalin $(A 1)$ indicate a lack of cross-reactivity between these two antibodies. Although the antibodies were raised against a single member of a peptide family, they probably recognize more than just that member because of the sequence similarities within peptide families (Morris et al., 1982; Mahon et al., 1985; Lloyd et al., 1987b; Miller et al., 1993). Thus, the antibodies will be referred to by the family they recognize, not the individual member they were raised against.

\section{Buccalin and SCP are found in the same processes}

The distribution of peptide staining in the ARC (Fig. 3B1,B2) is consistent with the known innervation of this muscle. Some processes stain for SCP and buccalin (black arrowheads), indicating that they belong to $\mathrm{B} 15$, whereas other processes (white arrowheads) stain only for buccalin, indicating that they belong to B16. There appears to be relatively little overlap between the B15 and B16 innervation of the ARC because the two types of processes are found in distinct locations of the ARC, often separated by tens of micrometers. Because B15 is the only neuron in the buccal ganglion to stain for both SCP and buccalin, and because costaining processes do occur in the ARC, costaining for SCP and buccalin is a convenient way of identifying B15 innervation in the ARC.

\section{Buccalin, like SCP, is stored in large dense-core vesicles and not in small clear vesicles}

Three lines of evidence enable the unequivocal identification of B15 processes in the ARC. First, B15 and B16 are the only motorneurons known to innervate the ARC (Cohen et al., 1978). Second, B15 is the only neuron in the buccal ganglion that stains for both SCP and buccalin. Third, B16 terminals do not contain large dense-core vesicles (DCVs) (Kreiner et al., 1987). Previous work has shown that SCP is localized in DCVs and not in the small clear vesicles (SCVs) of the ARC (Cropper et al., 1987a). As reported previously (Kreiner et al., 1987) for the terminals of B15 in the ARC muscle, the clear vesicles had a diameter of $\sim 70 \mathrm{~nm}$, whereas the dense-core vesicles had an average diameter of $\sim 120$ $\mathrm{nm}$. The SCVs in this and other systems are thought to contain the primary transmitter, whereas the DCVs are thought to contain the peptide cotransmitters. Thus, it is not surprising that buccalin is also present in DCVs within B15 motor terminals (Fig. 4). A vast majority of gold particles corresponding to buccalin in Figure 4 are associated with DCVs, and the staining associated with SCVs 


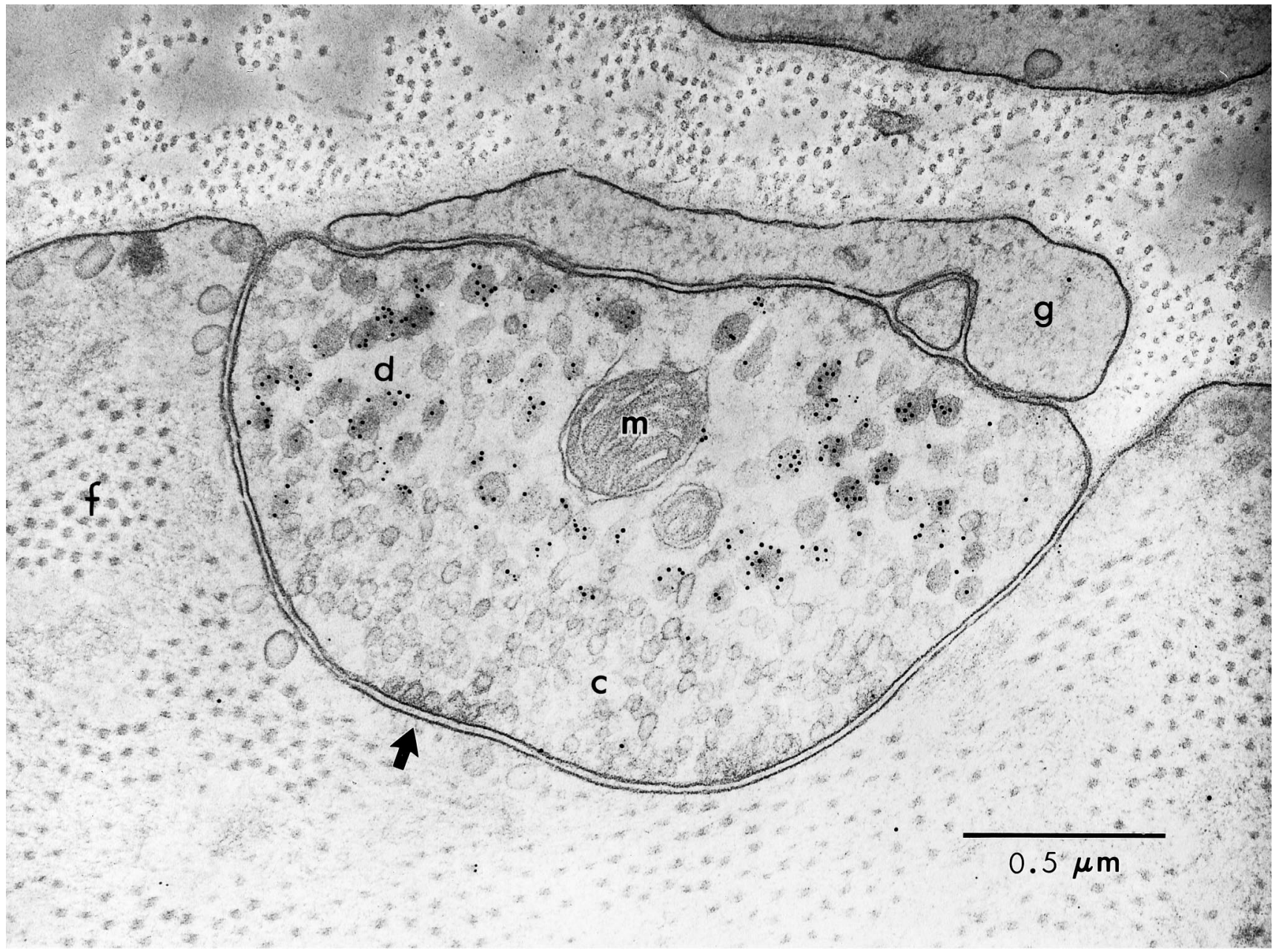

Figure 4. Postembedding immunogold labeling of buccalin and SCP in a B15 neuromuscular junction of the ARC. Cross section of a muscle fiber and B15 terminal in the ARC stained for buccalin (10 nm gold) and SCP (5 nm gold). The presence of buccalin and SCP staining identifies this as a B15 terminal. Note that peptide staining is over the DCVs, not the SCVs, and that many DCVs stain for both buccalin and SCP. The arrow points to an active zone with a number of docked SCVs; note the absence of postsynaptic specializations. $f$, Myofibrillar bundle in the muscle fiber; $g$, capping glial process; $m$, mitochondrion in B15 terminal; $c$, small clear synaptic vesicles; $d$, large dense-core vesicles. Scale bar, $0.5 \mu \mathrm{m}$.

was indistinguishable from background levels. The smaller gold particles associated with the DCVs correspond to SCP staining, demonstrating that the terminal belongs to B15. Many DCVs stain for both buccalin and SCP (large and small gold), whereas many also show staining for buccalin alone.

\section{SCP and buccalin are stored in the same dense-core vesicles}

Figure 5, $A 1$ and $B 1$, also shows numerous DCVs staining for both SCP (large particles) and buccalin (small particles). As in Figure 4, there are many DCVs that stain for buccalin alone. The sizes of the gold particles used to visualize buccalin and SCP are reversed in Figures 4 and 5, yet the distribution of staining is quite similar. This indicates that the more widespread buccalin staining is not an artifact caused by the size of the gold particles. In Figure 5, $A 1$ and $A 2$ show serial sections of the same terminal. In $A 2$, the antibody to buccalin was adsorbed with $50 \mu \mathrm{M} \mathrm{BUCa}$, and the small particles corresponding to the buccalin staining disappear, leaving only the larger gold particles corresponding to the SCP staining over the DCVs. $B 1$ and $B 2$ also show serial sections of the same terminal. In $B 2$, the antibody to SCP was adsorbed with $50 \mu \mathrm{M} \mathrm{SCPb}$, and the large gold particles corresponding to the SCP staining disappear, leaving only the small particles corresponding to the buccalin staining over the DCVs. Thus, the costaining of the DCVs for SCP and buccalin is unlikely to be an artifact of cross-reactivity, because adsorption of the primary antibodies with $50 \mu \mathrm{M}$ of the appropriate peptide resulted in the selective disappearance of the corresponding staining.

Figure 6 shows the combined results from 117 micrographs (5 different preparations) of stained B15 terminals and processes which, taken together, indicate that SCP and buccalin are costored in all DCVs within B15 terminals. For each of the staining conditions, the data were combined simply by counting morphologically distinguishable DCVs that stained for either peptide alone, both peptides, or neither peptide and expressing that population as a percentage of the total DCVs. This type of analysis was possible because the background staining was low and because both sides of the sections were exposed to antibody. A DCV was considered labeled if it had a gold particle within $15 \mathrm{~nm}$ of its perimeter, because the dimensions of an antibody molecule can allow the gold particle to lie this distance away from the peptide's antigenic site (Ottersen, 1989). 

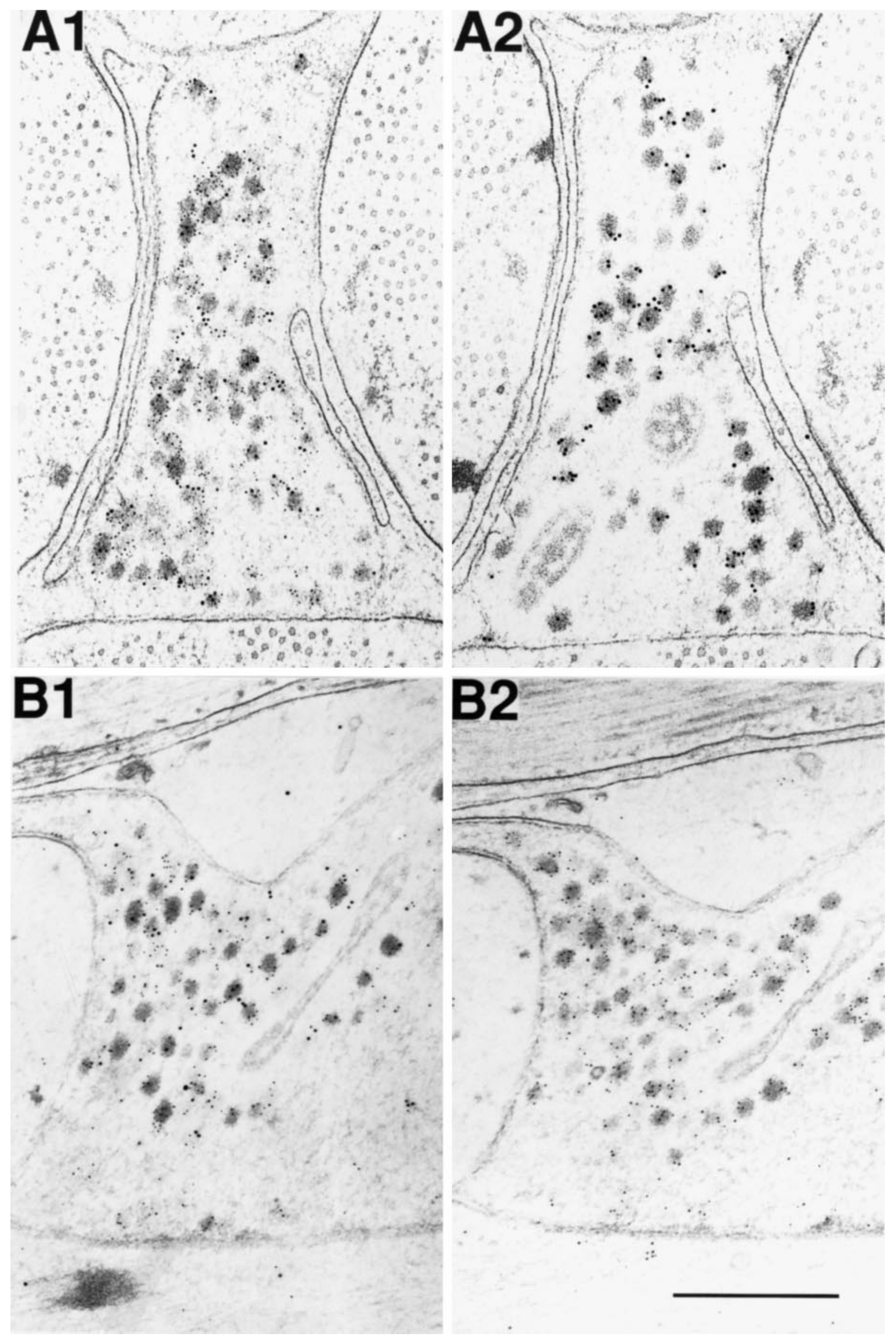


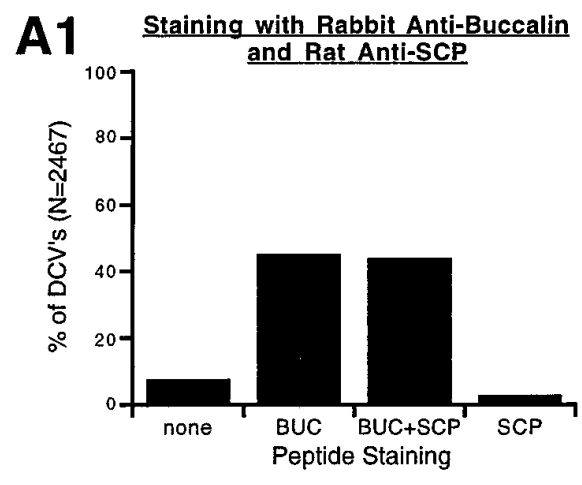

Figure 6. Summary of data obtained from immunogold double labeling of B15 terminals in the ARC. Bars represent the percentage of dense-core vesicles that stained for the peptide indicated below the bar. A densecore vesicle was considered labeled if a gold particle was within $15 \mathrm{~nm}$ of its perimeter The total number of DCVs used to generate the graph is indicated on the $y$-axis. A1, Rabbit anti-buccalin and rat anti-SCP staining resulted in double labeling of about half of the DCVs. A2, Rabbit anti-SCP and rat antiSCP staining also resulted in double labeling of about half of the DCVs, suggesting that differences in antibody potency, not differential localization, account for the staining pattern in $A 1$. Also note that $>90 \%$ of DCVs stain for SCP. B1, Omission or adsorption (with synthetic SCP) of the primary antibody to SCP results in disappearance of the corresponding label. Note that $>90 \%$ of densecore vesicles stain for buccalin. B2, Omission or adsorption (with synthetic buccalin) of the primary antibody to buccalin results in the disappearance of the corresponding label. These results indicate that SCP and buccalin are costored in all of the DCVs of B15.

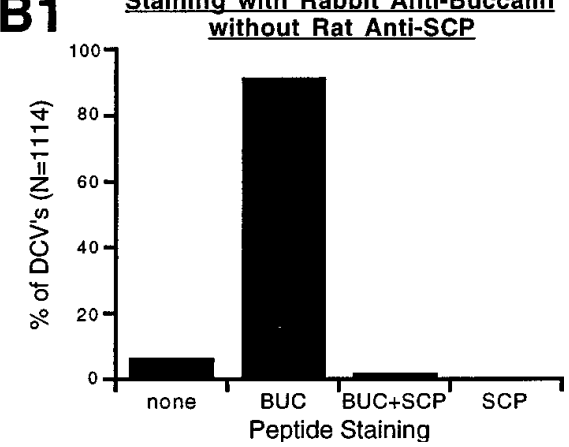

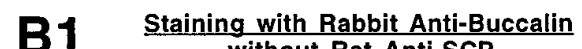
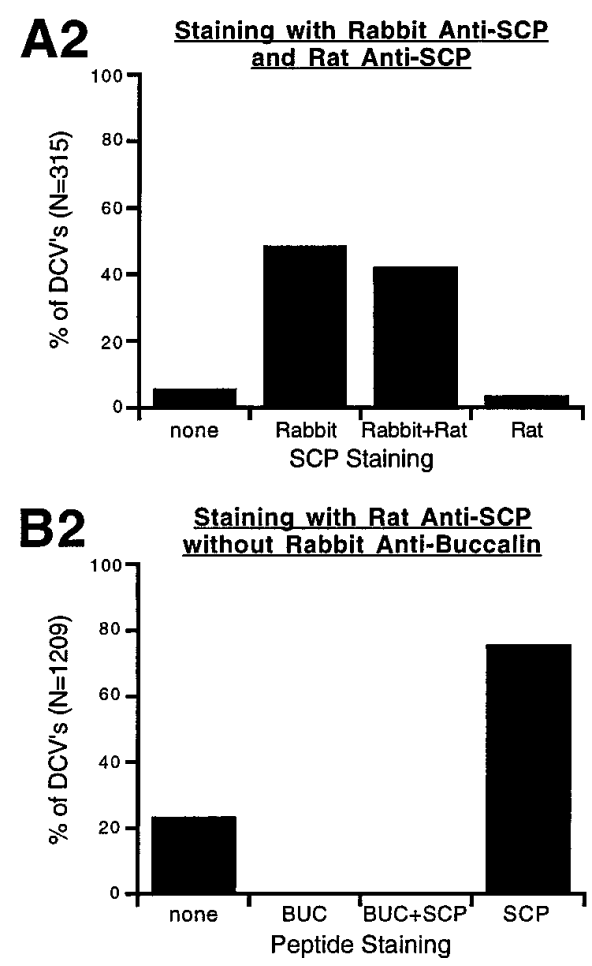

As shown in Figure $6 A 1$, labeling with rabbit anti-buccalin and rat anti-SCP resulted in costaining of $44.1 \%$ of DCVs, whereas another $45.2 \%$ stained for buccalin alone. This staining is likely to be specific because omission of the primary antibodies, or adsorption with $50 \mu \mathrm{M}$ BUCa $(B 1)$ or SCPb $(B 2)$, resulted in the absence of the corresponding staining. The DCVs that stained only for buccalin $(A 1)$ probably do not represent a distinct class of vesicles, because labeling with the rat anti-SCP and a rabbit anti-SCP $(A 2)$ produced a similar pattern of staining. In this case, $42.2 \%$ of DCVs stained for both rabbit and rat anti-SCP, whereas another $48.6 \%$ stained for rabbit anti-SCP alone. Because the antibodies recognize the same peptide, the pattern of staining must be attributable to the greater potency of the rabbit antibodies, suggesting that SCP and buccalin are costored in all of the DCVs of B15. Complete costorage is also suggested by the $94.3 \%$ of DCVs that stain for SCP in $A 2$ and the $93.4 \%$ of DCVs that stain for buccalin in $B 1$. Taken together, these results argue that all of the DCVs in B15 terminals of the ARC contain both SCP and buccalin and that selective release of these peptides is unlikely. However, it is important to stress that our immunocytological studies are not able to determine whether different dense-core vesicles contain different ratios of the SCPs and BUCs. Consequently, based on morphological studies alone we cannot exclude the possibility that populations of vesicles with differing ratios of peptides are released under different conditions. This issue, which has enormous functional implications, can only be addressed by directly measuring the relative amounts of peptides that are released under different physiologically relevant conditions.

\section{Peptides are released within the ARC after physiologically relevant motorneuron stimulation}

In developing a preparation to directly measure peptide release within the ARC, the ability to measure minute quantities of peptide was essential. RIA was the detection system of choice because it is relatively specific and can detect small amounts of peptide. In searching for antibodies that would give the greatest possible sensitivity, we observed that the antisera generated with BSA-conjugated peptides were far superior to those generated with BTG-conjugated peptides and that the antisera generated in rabbits were superior to antisera generated in rats. In fact, all of the antisera that were ultimately used for the RIAs were generated in rabbits against BSA-conjugated peptides.

Figure 7 shows the standard curves of the RIAs that were used to measure peptide release from B15. The RIAs that were eventually used to measure SCP release used the Morris rabbit anti$\mathrm{SCPb}$ at 1:5000 incubated for $2 \mathrm{~d}$, which gave a percent binding $(\% \mathrm{~B})$ of $55.50 \pm 0.9 \%$, a $50 \%$ displacement of counts bound $\left(\mathrm{IC}_{50}\right)$ of $11.04 \pm 0.46 \mathrm{fmol}$, and could detect less than $1 \mathrm{fmol}$ of $\mathrm{SCPb}$. The rabbit anti-BUCa coupled to BSA (rabbit 2, bleed 8) at $1: 10,000$ for $2 \mathrm{~d}$ gave a $\% \mathrm{~B}$ of $65.96 \pm 0.75 \%$, an $\mathrm{IC}_{50}$ of $18.38 \pm$ $1.29 \mathrm{fmol}$, and could detect $<1 \mathrm{fmol}$ of BUCa. The buccalin assay was 10-fold less sensitive to $\mathrm{BUCb}$ than to $\mathrm{BUCa}$ (data not shown).

Increasing the antibody dilution decreased $\% \mathrm{~B}$ and $\mathrm{IC}_{50}$, whereas prolongation of the incubation time generally increased $\% \mathrm{~B}$ and decreased $\mathrm{IC}_{50}$. The assays do not detect peptides from

Figure 5. Adsorption controls for immunogold labeling of SCP and buccalin in B15 terminals of the ARC. $A 1$ is a cross section stained for SCP (10 nm gold) and buccalin ( $5 \mathrm{~nm}$ gold) showing that many DCVs costain for both. $A 2$ is a serial cross section of the same process as $A 1$ stained in parallel, except that the buccalin primary antibody was pre-adsorbed with synthetic buccalin showing that only the SCP staining remains (10 nm gold). B1 is a longitudinal section stained for SCP (10 nm gold) and buccalin ( $5 \mathrm{~nm}$ gold), also showing that many DCVs costain for both. B2 is a serial longitudinal section of the same process as $B 1$ stained in parallel, except that the SCP primary antibody was adsorbed with synthetic SCP, showing that only the buccalin staining remains ( $5 \mathrm{~nm}$ gold). Scale bar (shown in $B 2$ ): $0.5 \mu \mathrm{m}$. 


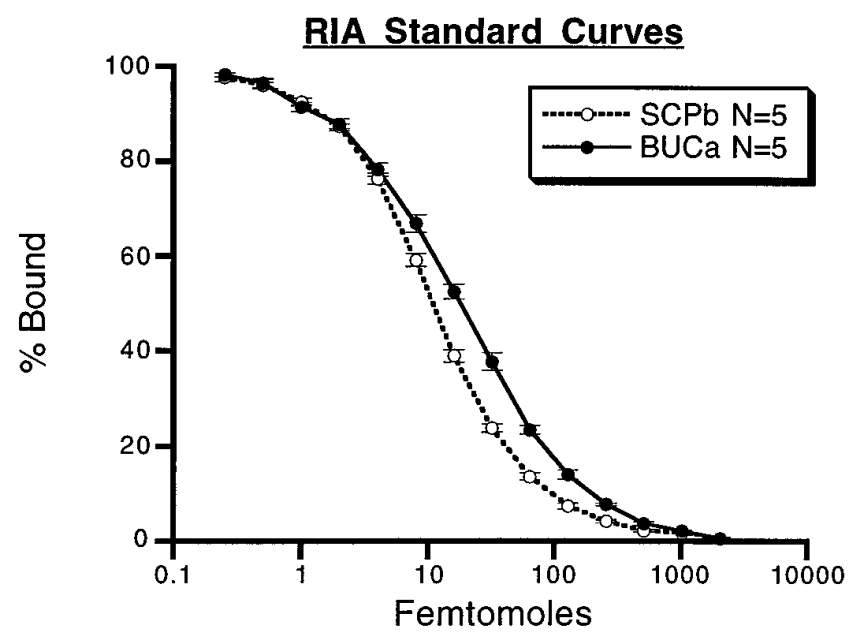

Figure 7. RIA standard curves for SCP and buccalin. The curves were generated with ${ }^{125} \mathrm{I}$-labeled peptide, peptide antibody, and serial dilutions of peptide standard. Femtomoles of unlabeled peptide are plotted against the percentage of counts bound to antibody. Zero peptide added was taken as $100 \%$ bound and typically accounted for approximately half of the total counts. Each data point is the average \pm SE of five separate standard curves generated over a 5 month period. The SCP assay used a 1:5000 dilution of antibody that bound $55.50 \pm 0.90 \%$ of the counts after a $2 \mathrm{~d}$ incubation. The SCP assay had an $\mathrm{IC}_{50}$ of $11.04 \pm 0.46 \mathrm{fmol}$. The buccalin assay used a 1:10,000 dilution of antibody that bound $65.96 \pm$ $0.75 \%$ of the counts after a $2 \mathrm{~d}$ incubation. The buccalin assay had an $\mathrm{IC}_{50}$ of $18.38 \pm 1.29 \mathrm{fmol}$. The RIAs are quite sensitive and are capable of detecting $<1$ fmol of peptide.

different families, and not all peptides within a family are detected equally well (data not shown). Because the relative binding of all of the members of families is unknown, comparative assays of the absolute amounts of different families is not possible. However, the relative amounts of a single family of peptides (e.g., the buccalins) can be gauged from one sample to the next because these are quantitatively related. Because the RIAs are probably measuring the release of more than one peptide cotransmitter within a family (D. Price, unpublished observations), the release of the family is referenced (i.e., $\mathrm{SCP}=\mathrm{SCPa}, \mathrm{b}$ and $\mathrm{BUC}=$ BUCa,b, etc.) in the release experiments. The geometry of the preparation used to measure release from the ARC was equally important for the measurement of peptide release. The quantities of peptides released in the ARC were expected to be low, so the dilution of these peptides was minimized. Furthermore, such small quantities of peptides tend to stick to plastics such as tubing, pipette tips, etc., so the contact of the peptides with such materials was limited. These requirements were satisfied by isolating the ARC in a siliconized subchamber with minimal dead volume, slowly perfusing with ASW, and collecting the perfusate as drops directly into the test tubes that would be used subsequently in the measurement of their peptide content. The kinetics of peptide release within the ARC could also be examined with this arrangement. Finally, the isolation of the buccal ganglion in a dish containing elevated $\mathrm{MgCl}_{2}$ prevented spontaneous activity but permitted individual motorneurons to be impaled with microelectrodes, thus allowing the firing to be regulated.

Because the EM immunocytochemistry indicated that these peptide families are costored in the same DCVs, we expected that these peptides would also be coreleased. In Figure 8, alternate samples (2.5 min each) of ARC perfusate were analyzed for either their SCP or their BUC content. After collecting a baseline for 30 min, motorneuron B15 was fired for $1 \mathrm{hr}$ (black bars), a period that is less than the duration of a normal meal, and in a pattern and frequency that matched the pattern and frequency recorded during normal feeding (Cropper et al., 1990c) but did not reflect the variability of the frequencies and patterns that occur in normal meals. During the next 30 min period, the motorneuron was not fired.

Figure $8 A 1$ shows the results from a single experiment in which motorneuron B15 was fired at $12 \mathrm{~Hz}$ for $3.5 \mathrm{sec}$ every $7 \mathrm{sec}$ during the period indicated by the black bar. The SCP and buccalin content in the perfusate increases after stimulation of B15, reaches a peak, and then declines, even though the motorneuron continues to be stimulated. A further decline is observed after termination of motorneuron stimulation. This pattern of release is not caused by a decrease in the health of the preparation, because the pattern is repeatable in the same preparation and many preparations remain viable for $>12 \mathrm{hr}$. Figure $8 B 1$ illustrates the combined results from four preparations under the same conditions. Because the absolute amounts of the peptides detected varied in different experiments, the release was normalized to the ability of the preparation to release peptides. The SCP and BUC content in each $5 \mathrm{~min}$ bin is normalized to the total of all of the buccalin and SCP detected in the experiment. Identical bins in each of the four experiments are then averaged $( \pm S E)$ and plotted against time (sample number). These data mirror the results from the single experiment, showing that the SCP and BUC content increases, reaches a peak, and then declines as the motorneuron is stimulated with its in vivo firing pattern (Cropper et al., 1990c). A return of peptide content to the baseline level is seen after termination of motorneuron stimulation. These experiments provide clear evidence for the corelease of BUC and SCP from B15 terminals in response to a physiologically relevant stimulation rate and pattern of a single B15 motorneuron.

The similarity in release profiles for $\mathrm{BUC}$ and $\mathrm{SCP}$ content seen in Figure $8, A 1$ and $B 1$, is highlighted when the BUC content is scaled in such a manner that total BUC equals total SCP. In $A 2$, the BUC content in each sample collected during the stimulation of B15 is multiplied by 2.6 to scale it to the SCP content in the same period. In $B 2$, the BUC percent of total for each bin is multiplied by 2.4 to scale it to the SCP percent in the same period. The similarity between SCP and BUC profiles is consistent with their release from the same dense-core vesicles.

\section{Peptide release within the ARC changes with time}

The results shown in Figure 8 suggest that peptide release from the motorneurons in the ARC is not constant over time, even with constant stimulation. The decline in peptide content in the perfusate after continued motorneuron stimulation is most likely caused by a decrease in peptide release from the motorneurons. However, the increase in peptide release seen at the beginning of peptide stimulation could also be explained by the diffusion of the released peptide into the perfusate. This diffusion is difficult to quantify, so we used another approach to determine whether the peptide release increases in the initial stages of motorneuron stimulation.

Figure 9 shows the results from experiments in which the total duration of B15 stimulation was varied between 5 and $10 \mathrm{~min}$ while the other stimulation parameters were kept constant $(12 \mathrm{~Hz}$, $3.5 \mathrm{sec}$ on, $3.5 \mathrm{sec}$ off). An ABCA paradigm (i.e., 10, 7.5, 5, and 10 min) was used so that changes in peptide release over the course of the experiment could also be assessed and controlled for. $A$ shows the results from one such experiment in which SCP was measured. Reducing the total duration of stimulation diminished 
A1

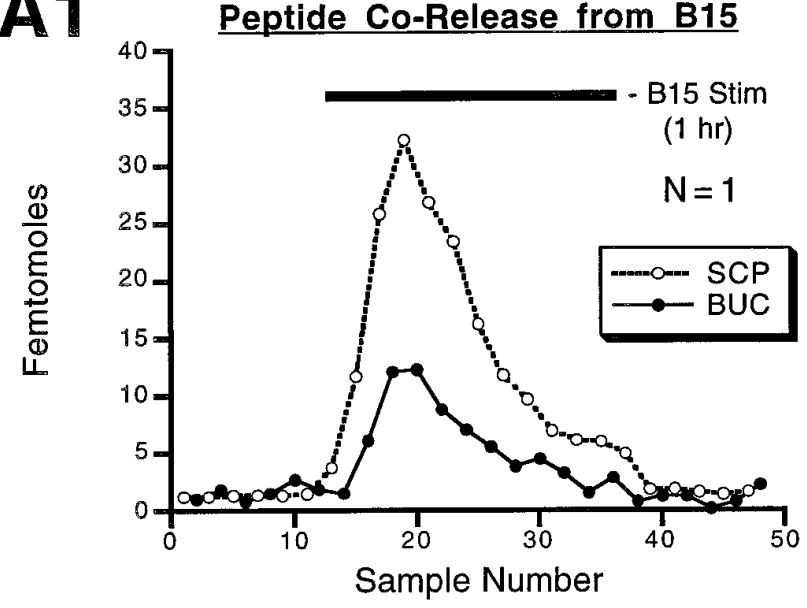

B1

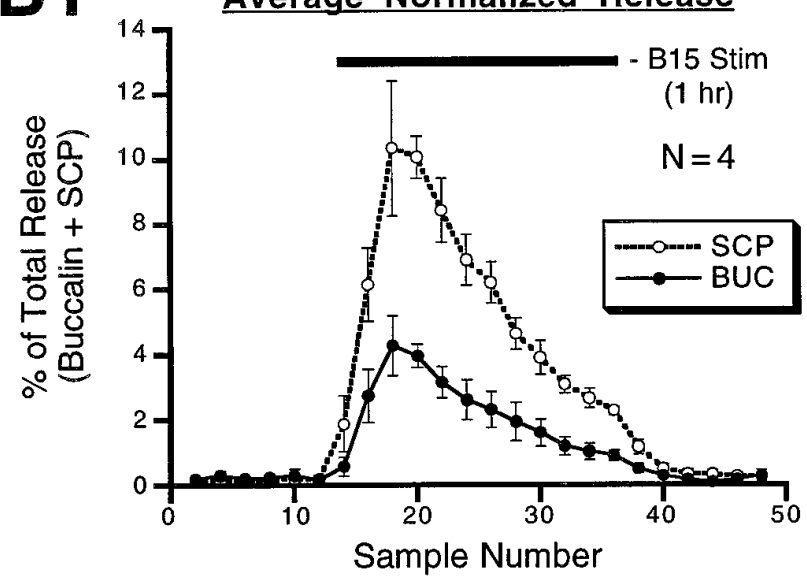

A2

Scaled Peptide Release from B15

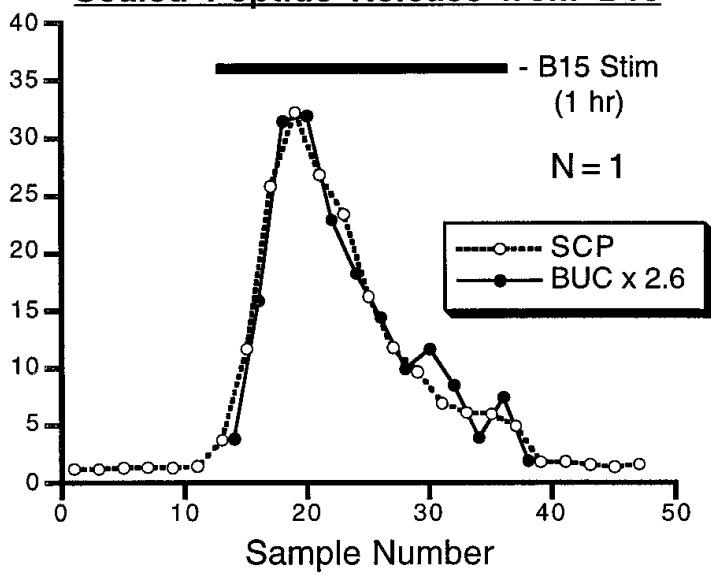

B2

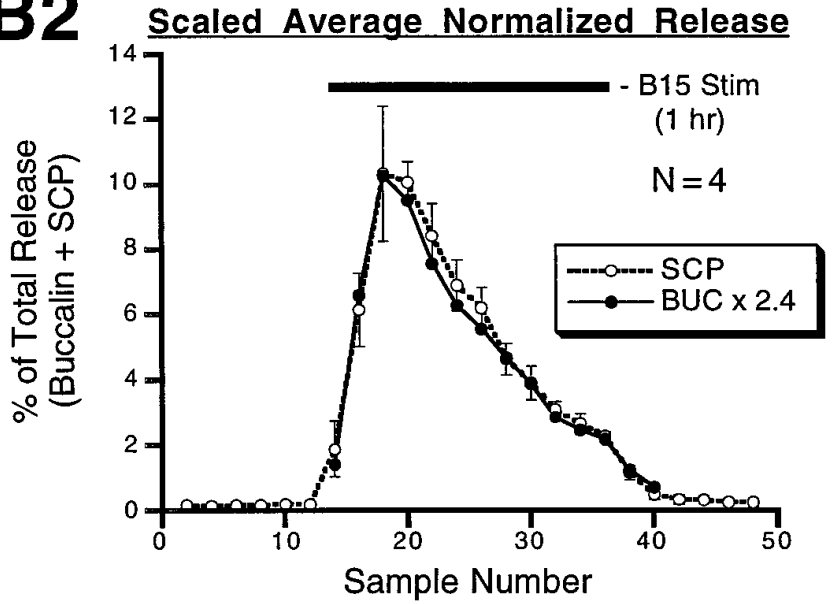

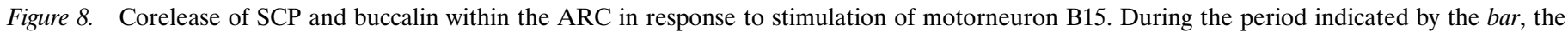

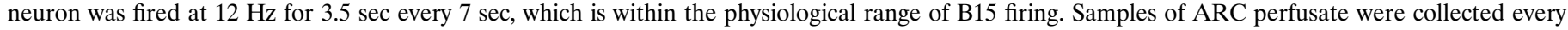

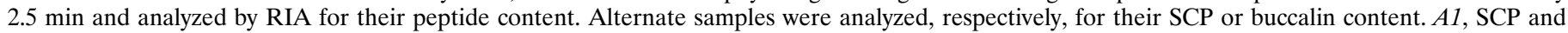

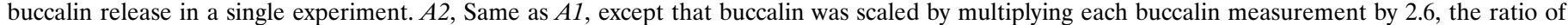

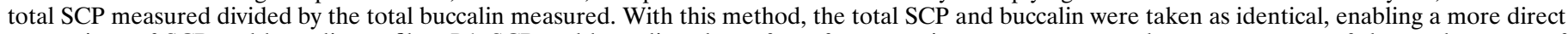

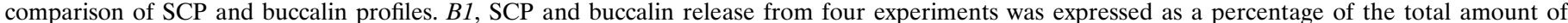

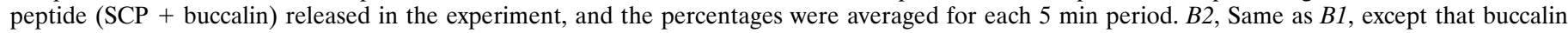

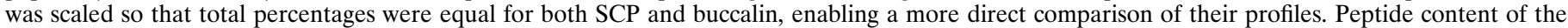
samples increases after stimulation of B15, reaches a peak, and then declines even though the neuron is still being stimulated. BUC, Buccalin.

the total amount of SCP measured in the same period. However, the total number of action potentials was not the same in these periods, so the difference could be attributable simply to a difference in the total number of action potentials delivered. That this is not the case is shown in $B$, in which release is expressed per action potential and is normalized for the ability of the preparation to release peptide by expressing the release at each duration within a single experiment as a percent of the average release for all three durations $(5,7.5$, and $10 \mathrm{~min})$. For BUC $(n=5)$ and SCP $(n=5)$, the mean \pm SE for the normalized release per action potential is then plotted against the total duration of stimulation. The results indicate that there was a significant overall increase in the release of SCP $\left(F_{(2,8)}=4.46 ; p<0.05\right)$ and for buccalin $\left(F_{(2,8)}\right.$ $=12.57 ; p<0.005)$. We observed a slight but significant increase in the amount of peptide released at $10 \mathrm{~min}$ compared to $5 \mathrm{~min}$ $(p<0.05)$, suggesting that peptide release does, in fact, increase in the initial phases of motorneuron stimulation.

\section{Peptide release is calcium-dependent}

Peptide release in a number of systems is calcium-dependent. In many of these systems, the calcium dependence of peptide cotransmitter release has been used as a control to rule out the nonspecific release of cellular contents attributable to the toxicity of the stimulation method (e.g., massive depolarization by means of $\mathrm{KCl}$; Mason et al., 1984). Calcium dependence of peptide cotransmitter release also gives some insight into the cellular mechanisms responsible for the release. Figure 10 shows the results from experiments in which the extracellular calcium concentration was changed in each of four 25 min periods in which B15 stimulation parameters were kept constant $(12 \mathrm{~Hz}, 3.5 \mathrm{sec}$ on, $3.5 \mathrm{sec}$ off, $10 \mathrm{~min}$ duration). The calcium concentration in the perfusate was altered simply by replacement with magnesium. An ABCA paradigm (i.e., 11, 5.5, 0, and $11 \mathrm{~mm}$ ) was used so that changes in peptide release over time could also be assessed and controlled for. Figure $10 A$ shows the results from one such ex- 

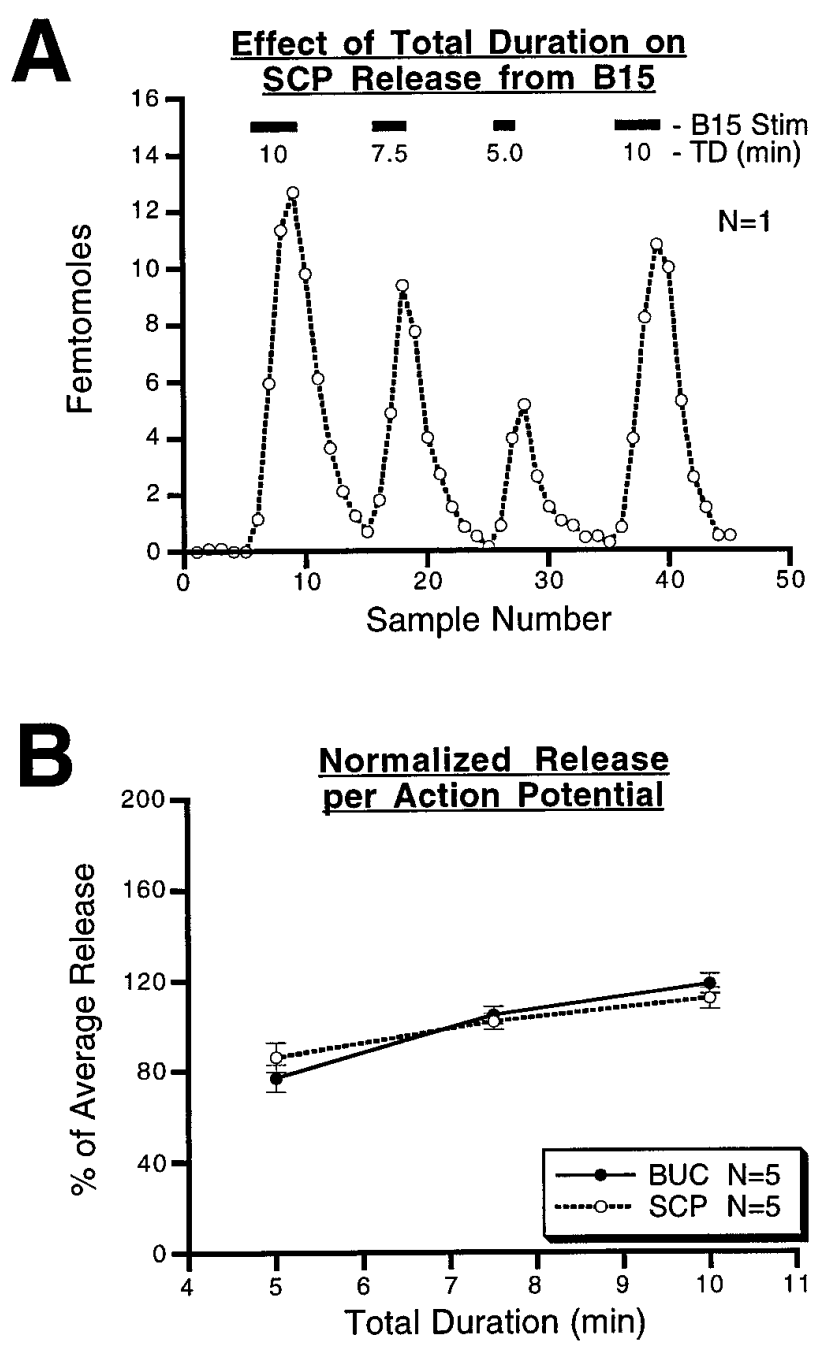

Figure 9. Effect of the total duration of B15 stimulation on peptide release within the ARC. $A$, Results from a single experiment in which SCP release is measured continuously while periods of stimulation of varying duration are applied; the interburst interval $(3.5 \mathrm{sec})$, the intraburst frequency $(12 \mathrm{~Hz})$, and the duration of bursts $(3.5 \mathrm{sec})$ were kept constant. $\mathrm{SCP}$ release increases as the period of stimulation lengthens, but the number of action potentials delivered also increases. $B$, The total released peptide at each of the three durations is corrected to give the release per action potential. This value for each of the three total durations was normalized to the average release for that experiment. The resulting percentage of average release from five separate experiments for each peptide was averaged for each of the three durations. For each peptide, the mean percentage of average release \pm SE is plotted against the duration. The results are similar for the two peptides and indicate that there is a slight, but significant, increase in the amount of peptide released per action potential as the duration increases from 5 to $10 \mathrm{~min}$. BUC, Buccalin.

periment in which SCP was measured. Reducing the calcium concentration lowered the total amount of SCP measured in the same period, and these effects seemed to be completely reversible. Figure $10 B$ shows the combined results from eight experiments, four for each peptide. The results indicate a significant increase $\left(F_{(2,6)}=425.5 ; p<0.0001\right.$ for buccalin; $F_{(2,6)}=1794.3 ; p<$ $0.0001)$ in peptide release as the extracellular calcium concentration is increased, demonstrating that peptide release is calciumdependent. For both peptides, individual comparisons of conditions in which calcium was lowered revealed a significant $(p<$ 0.01 ) depression of peptide release.
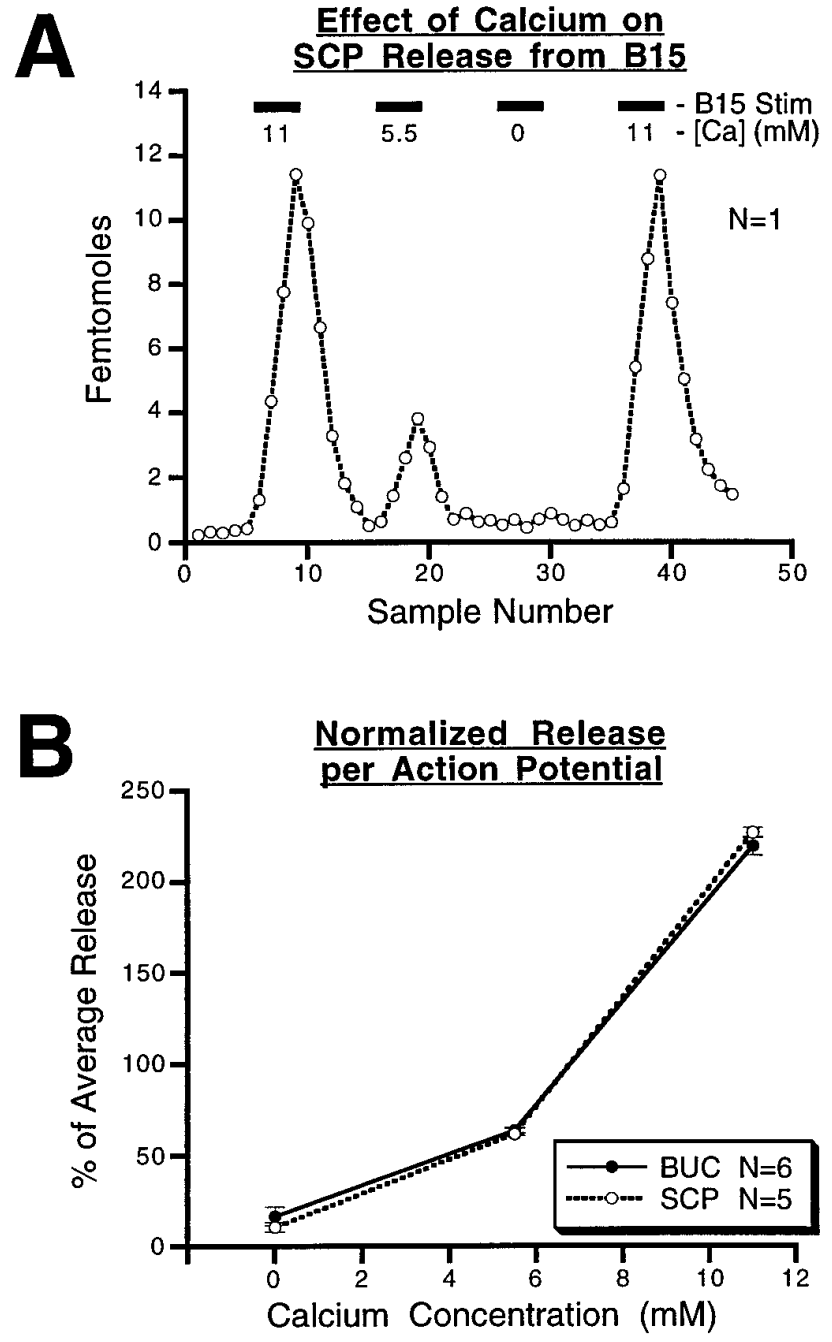

Figure 10. Effect of extracellular calcium concentration on peptide release from $\mathrm{B} 15$ in the ARC. $A$, Results from a single experiment in which SCP release is measured at different calcium concentrations in the perfusate while the intraburst frequency $(12 \mathrm{~Hz})$, the burst duration $(3.5 \mathrm{sec})$, the interburst interval $(3.5 \mathrm{sec})$, and the total duration $(10 \mathrm{~min})$ are kept constant. SCP release increases with the calcium concentration. $B$, The total released peptide at each of the calcium concentrations is normalized to the average release for that experiment. The resulting percentage of average release from five separate experiments for SCP, and six separate experiments for buccalin, was averaged for each of the three calcium concentrations. For each peptide, the mean percentage of average release $\pm \mathrm{SE}$ is plotted against the calcium concentration. The results are similar for the two peptides, indicating that the release of both peptides from B15 is calcium-dependent. BUC, Buccalin.

\section{Peptide release is independent of muscle contraction}

An ARC preparation with pharmacologically blocked contractions is an important control for the possibility that peptide release is an artifact caused by the contraction of the ARC, e.g., that the peptides are simply being squeezed out of some extracellular store by muscle contraction. This possibility was ruled out by blocking muscle contractions with hexamethonium, which blocks the depolarization produced by acetylcholine in this neuromuscular system (Cohen et al., 1978). The results of these experiments are shown in Figure 11. As shown in $A$, in a single experiment BUC was measured and motorneuron B15 was stimulated $(12 \mathrm{~Hz}$, 

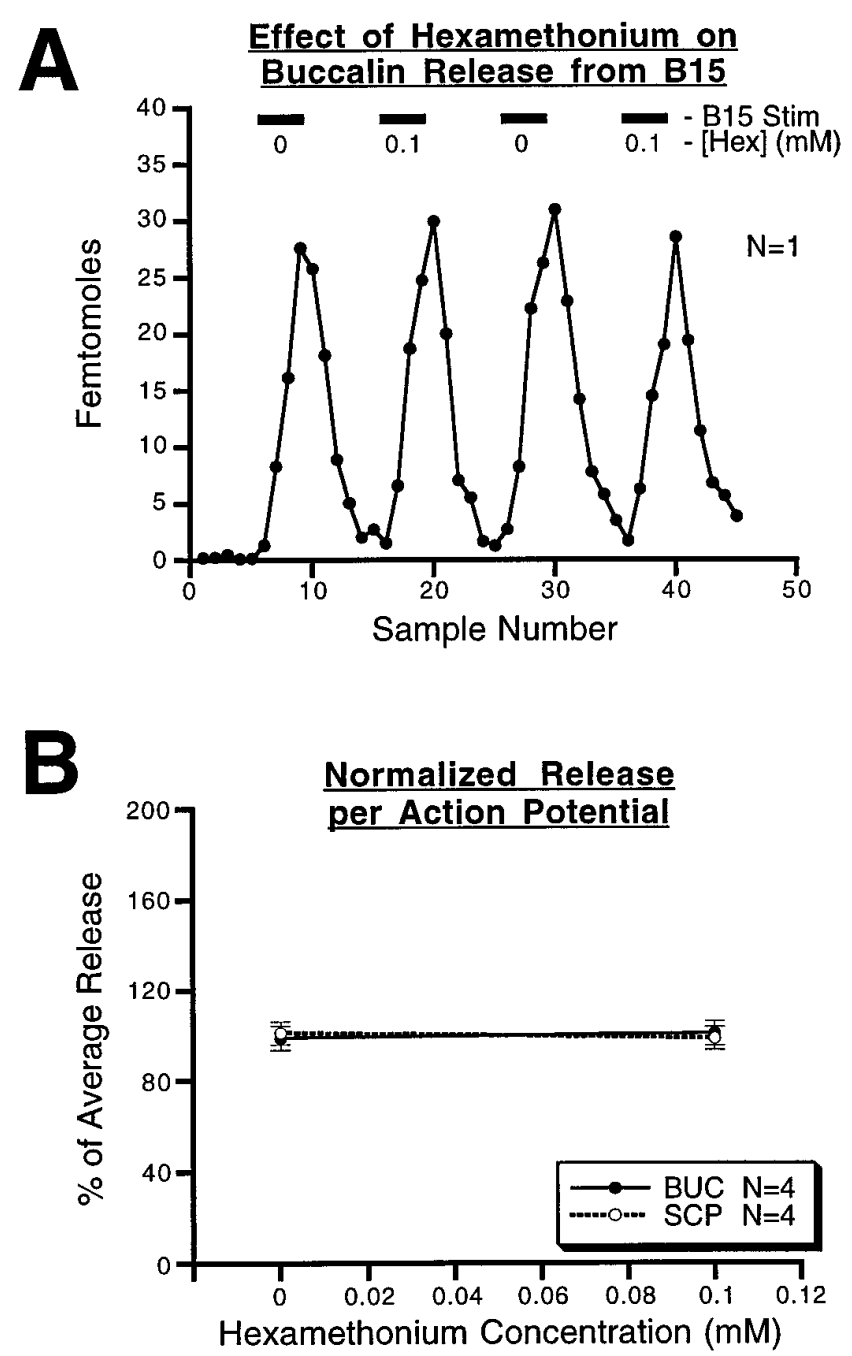

Figure 11. Effect of hexamethonium on peptide release from B15 in the ARC. $A$, Results from a single experiment in which buccalin release is measured in the presence or absence of $10^{-4} \mathrm{M}$ hexamethonium chloride, which blocks the acetylcholine receptors responsible for generating contraction. The stimulation parameters were all identical. Buccalin release is unaffected by the presence of this $\mathrm{ACh}$ antagonist. $B$, The total released peptide at the two hexamethonium concentrations is normalized using the average release for that experiment. The resulting percentage of average release from four separate experiments for each peptide was averaged for both of the hexamethonium concentrations. For each peptide, the mean percentage of average release \pm SE is plotted against the hexamethonium concentration. The results are similar for the two peptides and indicate that peptide release from B15 is unaffected by muscle contraction. BUC, Buccalin.

$3.5 \mathrm{sec}$ on, $3.5 \mathrm{sec}$ off, $10 \mathrm{~min}$ duration) in each of four $25 \mathrm{~min}$ periods. An ABAB paradigm was used in which $10^{-4} \mathrm{M}$ hexamethonium chloride was present in the perfusate in the second and fourth stimulation periods to completely block the ARC contraction (data not shown). Blocking ARC contractions with hexamethonium had no effect on the peptide content of the samples, indicating that release was unaffected. The combined data from eight experiments, four measuring each peptide (Fig. 10B), show that blocking the ARC contractions had no effect on SCP or BUC release within the ARC ( $p>0.8$ for each of the peptides). Thus, the release of peptides from the ARC is not caused by the contraction of the muscle squeezing out peptides trapped in the muscle tissue.

\section{DISCUSSION}

If peptide cotransmitters play a role in normal behavior, then their release under physiologically relevant conditions should be demonstrable. In previous studies of vertebrate systems, indirect measurements of peptide release have often been used, e.g., depletion, elevation of second messengers (Uchida et al., 1990), and the appearance of effects that mimic exogenous peptide application (Andersson et al., 1982; Jan and Jan, 1983). Moreover, nonphysiological stimulation has been used, including high potassium (Mason et al., 1984), ionophores (Verhage et al., 1991), or abnormally high rates of stimulation (Uchida et al., 1990). Stimulation of mixed nerves, in which the elements releasing the peptides are not known with certainty (Sakaguchi et al., 1991; Torres et al., 1992; Stjarne et al., 1986), has also been used. Even in the invertebrates, experiments open to alternative interpretations have been used as evidence for peptide release from single motorneurons (Adams and O'Shea, 1983; Tublitz and Truman, 1985; Li and Calabrese, 1987; Whim and Lloyd, 1989, 1990; Cropper et al., 1990b). In contrast, this study is based on a direct measurements of peptide release. Additionally, it is unique in that it establishes peptide cotransmitter release from single neurons under physiological conditions of neuronal firing.

\section{The ARC is an advantageous preparation for studying cotransmission}

The accessory radula closer and its innervation constitute an advantageous system for studying the behavioral role of peripheral neuromodulation and cotransmission. This muscle is innervated by only two cholinergic motorneurons that contain bioactive neuropeptides. When exogenously applied, these peptides modulate the muscle contractions. The simplicity of this preparation increases the probability of establishing a functional connection between cellular processes of cotransmission and the regulation of behavior. Even in this simple system, however, one cannot even begin to understand the function of cotransmission without understanding the conditions under which neuropeptides are being released. The presence of partially antagonistic transmitter molecules within one neuron makes this undertaking even more challenging. To characterize the release and possible functions of neuropeptides, we used a combination of morphological, electrophysiological, and biochemical techniques. First, we characterized the subcellular localization of the partially antagonistic neuropeptides and then proceeded to characterize the conditions under which these peptides are released.

\section{Peptide cotransmitters with partially antagonistic actions are stored within the same DCVs in motorneuron terminals of the ARC}

Previous evidence indicated that the SCPs are stored in DCVs and not SCVs within motor terminals in the ARC (Cropper et al., 1987a). The motorneurons have been shown to synthesize the peptides whose localization is being studied immunocytochemically, eliminating the cross-reactivity that can cast doubt on immunocytochemical findings. Finding neuronal processes in the ARC that stain for buccalin and SCP provides strong evidence that they belong to $\mathrm{B} 15$. The processes that stain for buccalin and not SCP are likely to belong to B16.

The buccalins, like the SCPs, are stored in large dense-core vesicles of motorneuron B15. Although the buccalins and SCPs have partially antagonistic actions, they are stored within the same DCVs. This finding suggests that SCP and buccalin are not released independently from motorneuron B15. However, these 
results do not exclude the possibility that different subpopulations of DCVs contain different ratios of SCPs and BUCs and are differentially released. This possibility was excluded by the experiments in this and the companion paper (this issue), in which we measured the relative amounts of BUCs and SCPs released under different conditions of stimulation.

\section{Peptide cotransmitters are likely to be released during normal behavior}

The indirect evidence for SCP release within the ARC includes depletion of SCP, elevation of cAMP, stimulation of PKA activity (Hooper et al., 1994a,b), and an increase in the muscle's relaxation rate after physiological or higher rates of motorneuron stimulation (Whim and Lloyd, 1989, 1990; Cropper et al., 1990b). However, the depletion was quite modest $(20 \%)$, and a priori one cannot exclude the release of substances other than SCP that can elevate cAMP, stimulate PKA, and increase the rate of muscle relaxation. Because the length of the high rate stimulation, lasting from 1 to $5 \mathrm{hr}$, may increase the intracellular levels of calcium leading to calcium toxicity, the physiological meaning of these experiments remains questionable. Thus, we developed a preparation that allowed us to directly measure peptide release in response to the stimulation of single motorneurons.

When motorneuron B15 is stimulated, buccalin and SCP appear in the perfusate with identical kinetics. This similarity in release profiles is consistent with corelease from the same DCVs. Thus, the ultrastructural immunocytochemistry and similarity in release kinetics both point to costorage of SCP and buccalin in the same DCVs. The release of modulatory peptides changes over time and, therefore, is reminiscent of the post-tetanic potentiation and depression described for primary transmitter release. After stimulation of the motorneuron, the release of peptide increases, reaches a peak, and then declines, even though the motorneuron continues to be stimulated. The depression of peptide cotransmitter release within the ARC could result from depletion of the releasable pool, although results from separate experiments suggest that $<20 \%$ of the peptide should be depleted from B15 under these conditions (Cropper et al., 1990b). These results parallel those reported for depression of ACh release in other systems in which there was no corresponding decrement in the number of clear vesicles located in the neuromuscular junction (for review, see Zucker, 1989). Independent of the mechanisms responsible for the depression of release, these results indicate that caution should be exerted in interpreting the quantitative aspect of release experiments using the depletion paradigm. In view of the complex temporal pattern of release, it is clear that calculation of peptide released per action potential in depletion experiments may not be meaningful. Peptide cotransmitters are probably released and exert their effects in the first few trains of action potentials, because observations of relaxation rate show an increase within the first few contractions (Cropper et al., 1990b; Whim and Lloyd, 1990). It is possible that even after prolonged firing of motorneurons, the smaller amount of peptide released may be able to sustain the physiological actions elicited by the larger amounts of peptides that were released during the initial stages.

The calcium dependence of peptide cotransmitter release has been reported in other systems (Adams and O'Shea, 1983; Mason et al., 1984; Uchida et al., 1990; Willard, 1990; Sakaguchi et al., 1991; Verhage et al., 1991; Torres et al., 1992); however, the removal of extracellular calcium also blocks muscle contraction, raising the possibility that the release was caused by some nonspecific effects of the muscle contractions. In our studies, the appearance of peptides in the perfusate is unlikely to be an artifact, because the release can be blocked by the substitution of magnesium for extracellular calcium but is unaffected by the blockade of contractions by hexamethonium. Thus, peptide release seen after B15 stimulation is calcium-dependent but is independent of muscle contractions.

The direct demonstration of SCP release supports the hypothesis that the actions of the SCPs released in response to physiologically relevant stimulation of B15 (Cropper et al., 1990b) are responsible for the elevation of cAMP and enhancement of the size and relaxation rates of muscle contractions that were observed under similar conditions of stimulation. The second messenger for buccalin is not known, however, and the physiological action of the released peptide may be difficult to address. The depression of contractions caused by BUC release would be difficult to distinguish from receptor desensitization or muscle fatigue. At present, there are no antagonists available for BUCs, making it more difficult to assess the actions of released BUCs. Nevertheless, the BUCs (and the SCPs) released from motorneuron terminals in these experiments are probably exerting their modulatory effects on the muscle, because the concentration of all of these peptides in the perfusate $(\sim 1 \mathrm{nM})$ is in the range in which exogenously applied peptides begin to exert their modulatory effects (Vilim et al., 1994). Thus, even diluted out in the perfusate, the buccalins could still be exerting their modulatory effects, and the concentration at the release sites is likely to be many times higher than that in the perfusate, so these peptides should and are likely to exert physiological actions.

In summary, the direct measurement of peptide release during the intracellular stimulation of a single motorneuron provides unequivocal evidence of their release. The demonstration that peptides are released when the motorneuron is stimulated with its in vivo firing pattern provides strong evidence that the peptides are released during normal behavior. Furthermore, the released peptides seem to be exerting their modulatory effects on muscle contraction. Taken together, these results support the idea that the modulatory peptides present in the motorneurons act as an intrinsic modulatory system that may play a role in the generation of feeding behavior. In the next paper, the factors that regulate the release of these peptide cotransmitters will be used to test a hypothetical model (Weiss et al., 1992) for their role in generating normal feeding behavior.

\section{REFERENCES}

Adams ME, O’Shea M (1983) Peptide cotransmitter at a neuromuscular junction. Science 221:286-289.

Andersson PO, Bloom SR, Edwards AV, Jaerhult J (1982) Effects of stimulation of the chorda tympani in bursts on submaxillary response in the cat. J Physiol (Lond) 322:469-483.

Brezina V, Bank B, Cropper EC, Rosen S, Vilim FS, Kupfermann I, Weiss KR (1995) Nine members of the myomodulin family of peptide cotransmitters at the B16-ARC neuromuscular junction of Aplysia. J Neurophysiol 74:54-72.

Church PL, Lloyd PE (1991) Expression of diverse neuropeptide cotransmitters by identified motor neurons in Aplysia. J Neurosci 11:618-625

Cohen JL, Weiss KR, Kupfermann I (1978) Motor control of buccal muscles in Aplysia. J Neurophysiol 41:157-180.

Cropper EC, Lloyd PE, Reed W, Tenenbaum R, Kupfermann I, Weiss KR (1987a) Multiple neuropeptides in cholinergic motor neurons of Aplysia: evidence for modulation intrinsic to the motor circuit. Proc Natl Acad Sci USA 84:3486-3490.

Cropper EC, Tenenbaum R, Kolks MAG, Kupfermann I, Weiss KR (1987b) Myomodulin: a bioactive neuropeptide present in an identified cholinergic buccal motor neuron of Aplysia. Proc Natl Acad Sci USA 84:5483-5486. 
Cropper EC, Miller MW, Tenenbaum R, Kolks MAG, Kupfermann I, Weiss KR (1988) Structure and action of buccalin: a modulatory neuropeptide localized to an identified small cardioactive peptidecontaining cholinergic motor neuron of Aplysia californica. Proc Natl Acad Sci USA 85:6177-6181.

Cropper EC, Miller MW, Vilim FS, Tenenbaum R, Kupfermann I, Weiss KR (1990a) Buccalin is present in the cholinergic motor neuron B16 of Aplysia and it depresses accessory radula closer muscle contractions evoked by stimulation of B16. Brain Res 512:175-179.

Cropper EC, Price D, Tenenbaum R, Kupfermann I, Weiss KR (1990b) Release of peptide cotransmitters from a cholinergic motor neuron under physiological conditions. Proc Natl Acad Sci USA 87:933-937.

Cropper EC, Kupfermann I, Weiss KR (1990c) Differential firing patterns of the peptide-containing cholinergic motor neurons B15 and B16 during feeding behavior in Aplysia. Brain Res 522:176-179.

Cropper EC, Vilim FS, Alevizos A, Tenenbaum R, Kolks MAG, Rosen SC, Kupfermann I, Weiss KR (1991) Structure, bioactivity, and cellular localization of myomodulin B: a novel Aplysia peptide. Peptides 12:683-690.

Fiore L, Geppetti L (1981) Neural control of buccal mass activity in Aplysia. Adv Physiol Sci 23:201-223.

Hooper SL, Probst WC, Cropper EC, Kupfermann I, Weiss KR (1994a) SCP application or B15 stimulation activates cAPK in the ARC muscle of Aplysia. Brain Res 657:337-341.

Hooper SL, Probst WC, Cropper EC, Kupfermann I, Weiss KR (1994b) Myomodulin application increases cAMP and activates cAMPdependent protein kinase in the accessory radula closer muscle of Aplysia. Neurosci Lett 179:167-170.

Jan YN, Jan LY (1983) A LHRH-like peptidergic neurotransmitter capable of "action at a distance" in autonomic ganglia. Trends Neurosci $6: 320-325$.

Kreiner T, Kirk MD, Scheller RH (1987) Cellular and synaptic morphology of a feeding motor circuit in Aplysia californica. J Comp Neurol 264:311-325.

Kupfermann I (1991) Functional studies of cotransmission. Physiol Rev 71:683-732.

Li C, Calabrese RL (1987) FMRF-amide-like substances in the leech. III. Biochemical characterization and physiological effects. J Neurosci 7:595-603.

Llewellyn-Smith IJ, Costa M, Furness JB (1985) Light and electron microscopic immunocytochemistry of the same nerves from whole mount preparations. J Histochem Cytochem 33:857-866.

Lloyd PE, Frankfurt M, Stevens P, Kupfermann I, Weiss KR (1987a) Biochemical and immunocytological localization of the neuropeptides FMRFamide, $\mathrm{SCPa}, \mathrm{SCPb}$, to neurons involved in the regulation of feeding in Aplysia. J Neurosci 7:1123-1132.

Lloyd PE, Kupfermann I, Weiss KR (1987b) Sequence of small cardioactive peptide A: a second member of a class of neuropeptides in Aplysia. Peptides 8:179-184.

Mahon AC, Lloyd PE, Weiss KR, Kupfermann I, Scheller RH (1985) The small cardioactive peptides A and B of Aplysia are derived from a common precursor molecule. Proc Natl Acad Sci USA 82:3925-3929.

Mason TR, Peterfreund RA, Sawchenko PE, Corrigan AZ, Vale WW (1984) Release of the predicted calcitonin gene-related peptide from cultured rat trigeminal ganglion cells. Nature 308:653-655.

Merighe A, Polak JM, Fumagalli G, Theodosis DT (1989) Ultrastructural localization of neuropeptides and GABA in the rat dorsal horn: a comparison of different immunogold labeling techniques. J Histochem Cytochem 37:529-540.

Miller MW, Alevizos A, Cropper EC, Kupfermann I, Weiss KR (1992) Localization of buccalin-like immunoreactivity in the central nervous system and peripheral tissues of Aplysia californica. J Comp Neurol 320:182-195.

Miller MW, Beushausen S, Cropper EC, Eisinger K, Stamm S, Vilim FS, Vitek A, Zajc A, Kupfermann I, Brosius J, Weiss KR (1993) The buccalin-related neuropeptides: isolation and characterization of an Aplysia/cDNA clone encoding a family of peptide cotransmitters. J Neurosci 13:3346-3357.

Morris HR, Panico M, Karplus A, Lloyd PE, Riniker B (1982) Elucidation by FAB-MS of the structure of a new cardioactive peptide from Aplysia. Nature 300:643-645.

Ottersen OP (1989) Quantitative electron microscopic immunocytochemistry of neuroactive amino acids. Anat Embryol 180:1-15.

Probst WC, Cropper EC, Heierhorst J, Hooper SL, Jaffe H, Vilim F, Beushausen S, Kupfermann I, Weiss KR (1994) cAMP-dependent phosphorylation of Aplysia twitchin may mediate modulation of muscle contractions by neuropeptide cotransmitters. Proc Natl Acad Sci USA 91:8487-8491.

Quicke DLJ, Brace RC (1979) Differential staining of cobalt- and nickelfilled neurones using rubeanic acid. J Microsc 115:161-163.

Reed W, Weiss KR, Lloyd PE, Kupfermann I, Chen M, Bailey CH (1988) Association of neuroactive peptides with the protein secretory pathway in identified neurons of Aplysia californica: immunolocalization of SCPa and $\mathrm{SCPb}$ to the contents of dense core vesicles and the trans face of the Golgi apparatus. J Comp Neurol 272:358-369.

Sakaguchi M, Inaishi Y, Kashihara Y, Kuno M (1991) Release of calcitonin gene-related peptide from nerve terminals in rat skeletal muscle. J Physiol (Lond) 434:257-270.

Sossin W, Sweet-Cordero A, Scheller RH (1989) Dales hypothesis revisited: different neuropeptides derived from a common prohormone are targeted to different processes. Proc Natl Acad Sci USA 87:4845-4848.

Stjarne L, Lundberg JM, Astrand P (1986) Neuropeptide Y: a cotransmitter with noradrenaline and adenosine 5 '-triphosphate in the sympathetic nerves of the mouse vas deferens? A biochemical, physiological, and electropharmacological study. Neuroscience 18:151-166.

Torres G, Britan M, Huidobro JP (1992) Co-release of neuropeptide Y (NPY) and noradrenaline from the nerve terminals supplying the rat vas deferens: influence of calcium and the stimulation intensity. Neurosci Lett 148:39-42.

Tublitz NJ, Truman JW (1985) Intracellular stimulation of an identified neuron evokes peptide release in an insect. Science 228:1013-1015.

Uchida S, Yamamoto H, Iio S, Matsumoto N, Wang XB, Yonehara N, Imai I, Inoki R, Yoshida H (1990) Release of calcitonin gene-related peptide-like immunoreactive substance from neuromuscular junction by nerve excitation and its action on striated muscle. $J$ Neurochem 54:1000-1003.

Vilim FS, Cropper EC, Rosen SC, Tenenbaum R, Kupfermann I, Weiss KR (1994) Structure, localization and action of buccalin b, a bioactive peptide from Aplysia. Peptides 15:959-969.

Verhage M, McMahon HT, Ghijsen WEJM, Boomsma F, Scholten G, Weigant VM, Nicholls DG (1991) Differential release of amino acids, neuropeptides, and catecholamines from isolated nerve terminals. Neuron 6:517-524.

Wang LJ, Scheller RH (1991) Peptide processing and targeting in the neuronal secretory pathway. Science 251:1330-1335.

Weiss KR, Brezina V, Cropper EC, Hooper S, Miller MW, Probst WC, Vilim FS, Kupfermann I (1992) Peptidergic co-transmission in Aplysia: functional implications for rhythmic behaviors. Experientia 48:456-463.

Whim MD, Lloyd PE (1989) Frequency-dependent release of peptide cotransmitters from identified cholinergic motor neurons in Aplysia. Proc Natl Acad Sci USA 86:9034-9038.

Whim MD, Lloyd PE (1990) Neuropeptide cotransmitters released from an identified cholinergic motor neuron modulate neuromuscular efficacy in Aplysia. J Neurosci 10:3313-3322.

Willard AL (1990) A vasoactive intestinal peptide-like cotransmitter at cholinergic synapses between rat myenteric neurons in cell culture. J Neurosci 10:1025-1034.

Zucker RS (1989) Short term synaptic plasticity. Annu Rev Neurosci 12:13-31. 